\title{
Fisheries-to-School in Alaska: A Food Service Directors' Perspective
}

\author{
Pei Xu ${ }^{1}$, Quentin Fong ${ }^{2}$, Andrea Bersamin ${ }^{3}$ \& Betty Izumi ${ }^{4}$ \\ ${ }^{1}$ Department of Agricultural Business, California State University at Fresno, Fresno, USA \\ ${ }^{2}$ Marine Advisory Program, Sea Grant Alaska, Kodiak, USA \\ ${ }^{3}$ Institute of Arctic Biology, University of Alaska Fairbanks, Fairbanks, USA \\ ${ }^{4}$ School of Community Health, College of Urban and Public Affairs, Portland State University, Portland, USA \\ Correspondence: Pei Xu, Department of Agricultural Business, California State University at Fresno, $5245 \mathrm{~N}$ \\ Backer Avenue, M/S PB101, Fresno, CA 93740-8001, USA. E-mail: pxu@csufresno.edu
}

Received: December 3, 2014

Accepted: December 19, 2014

Online Published: January 20, 2015

doi:10.5539/ijbm.v10n2p142

URL: http://dx.doi.org/10.5539/ijbm.v10n2p142

\begin{abstract}
This study uses online survey data gathered from school food service directors working for Alaska's rural school district to understand: 1) if participating food service directors are interested in serving local fish and what are their preferred fish forms; 2) factors influencing their menu planning decisions; and 3) food service directors' perceived fish preferences from students. Results show that the majority of the surveyed school districts currently serve fish. Many respondents indicated that they are interested or very interested in serving fish patties and burgers and fewer are interested in serving fish tacos and wraps. Price and product availability are two important factors to change menu-planning decisions. About half of the surveyed respondents believed that their students like fish the same as they like other meats. Findings from this study provide insights to Alaska fish processors to help them understand school preferred fish forms and the opportunities to sell fish to schools.
\end{abstract}

Keywords: fish preference, Alaska food service director survey, student fish preference, fish-to-school

\section{Introduction}

Community food systems in rural Alaska are tied to local culture, geography and climate. (Loring \& Gerlach, 2009). In rural villages, consumption of traditional cuisine using locally produced food has diminished. The loss of local food culture has challenged the health and nutrition of rural Alaskan villagers, especially the youth (Goldsmith, 2007; Martin et al., 2008; Bersamin, 2006; 2008 NOT CITED). To increase locally available food resources and encourage the consumption of local foods among Alaskan students, a fisheries-to-school research program was developed. This study uses the opinions of food service directors to identify preferred fish for in school food preparation in Alaskan communities and to provide information to local entities that are interested in supplying Alaskan caught and processed fish to the school system.

Alaska's fishery industry including commercial fishing and fish processing is the backbone of the local economy. It produces a total value of approximately 6 billion USD (ASMI, 2013). In 2013, Alaska's commercial landings were 2.6 million metric tons valued at 1.8 billion USD (US Department of Commerce, Various Years). The great availability of fish, especially salmon, has not resulted in a satisfactory adoption of fish menus among local school districts. Research about the 31 (out of 54) school districts that have published their lunch menus online indicated that six of them do not provide any fish menu in their most recent lunch plan, published in October 2013. Websites of the 54 Alaskan school districts shows that only 25 school districts offer fish menus on a monthly base or more frequently. For the school districts that are already serving fish, it is unclear if the fish used are from local. A pioneer school district that has adopted local fish specified that schools are financially challenged to bear the high costs of procuring and processing fish. Providing fish menu from scratch has been cited as another barrier for the inclusion of fish in Alaskan's school lunch menus (Griffiths, 2012).

This study uses online survey data gathered from school food service directors in Alaska to understand: 1) if participating food service directors are interested in serving local fish and what are their preferred fish forms; 2) factors influencing their menu planning decisions; and 3) food service directors' perceived fish preferences from students. Findings from this study may interest Alaska local fish processors to help them understand the school preferred fish forms and the opportunities to sell fish to schools. 


\section{Literature Review}

The impact of fisheries-to-schools programs, which are modeled after the farm-to-school programs, is unknown. A review of existing farm-to-school studies can provide valuable insights into the farm-to-school practice and the economic impact. USDA launched its first farm-to-school program in the mid 1990s in Florida to improve schools' access to locally grown produces. Schools in California, Michigan, and Minnesota quickly started their own programs. Today farm-to-school programs are not only available in all lower 48 states (National Farm to School Network, 2013) but also in Alaska to help locally grown foods make their way to school lunch tables. The programs are understood as a bridge between the state's agriculture and its school procurement system. Increased consumption of locally grown foods and reduced food miles not only contributed to the local economy but also improved the health of students (Farm to School Program, 2010). Studies have revealed that farm-to-school programs helped students eat more fruits and vegetables and enhanced students' knowledge about healthy eating and sustainable agriculture (Izumi et al., 2010 a.) These programs also created a new marketplace for food producers to help them generate additional income to sustain low seasons and offer them an alternative market for surplus produces in good years (Izumi et al., 2010 a). For example, the consumption of locally grown vegetables, melons, beef and grain was found to contribute an additional $11 \%$ dollar return to Central Minnesota's local economy (Haynes, 2010). The high labor cost from the process of raw materials is cited as the major barrier for the adoption of farm-to-school program (Joshi et al., 2008).

\section{Data}

An online survey was administered from the $6^{\text {th }}$ to the $18^{\text {th }}$ in February 2012 to gather questionnaire information from food service directors in Alaska's 54 school districts. An invitation was sent to all districts and Resident Child Care Institute's youth facilities and a web link was provided to potential participants. Reminder emails were sent out during the survey period to enhance participations. Five respondents were randomly selected using a random number generator to receive a $\$ 50$ gift cards. We used an online survey in order to make the survey available to all potential respondents in Alaska school districts and provide us with feedback in a time-efficient manner. The online survey also allowed participating food service directors to take the survey at their convenience. Paper copies were also available in Alaska School Nutrition Association's 43rd annual conference, but only one respondent filled out the questionnaire.

The survey included 217 questions, 25 of which were related to the fisheries-to-school program and the remaining questions were about the consumption of other local foods. For the fisheries-to-school portion, questions asked include interests in purchasing Alaskan fish, whether the district serves local or imported fish, preferred fish forms, and perceived price of fish relative to other meats. The second section asked how students liked fish. The last section asked participants' demographics and their job duties. Figure 1 presents a summary of the information collected in the survey.

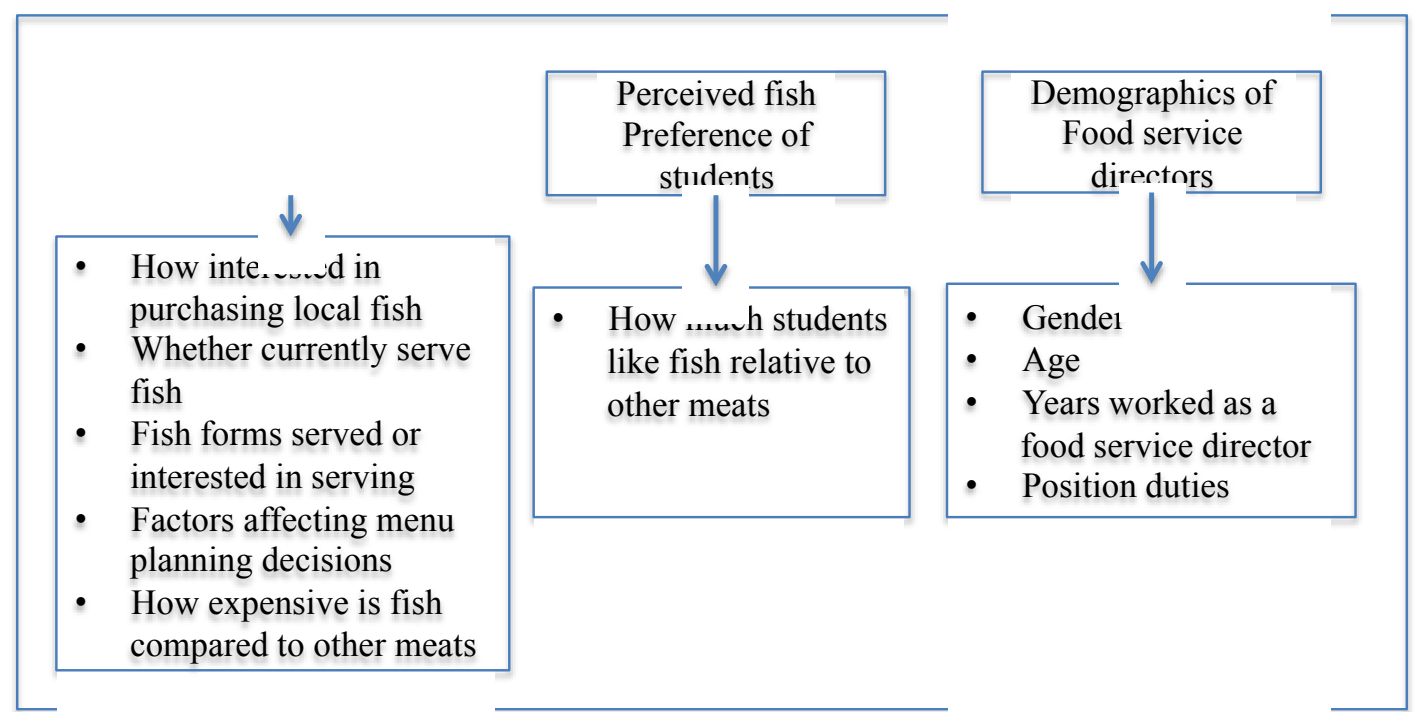

Figure 1. Information gathered in the 2012 spring survey 


\section{Results}

Forty-nine food service directors from 34 school districts responded to the online survey. If more than one participant from one school district completed the survey, a mean score was computed and used. The participating food service directors represent $63 \%$ of all 54 school districts in Alaska. These participating districts enroll 111,043 students in 2011, representing 92\% of all enrollments in Alaska schools.

\subsection{Enrollment of Participating School Districts and their Location}

Our sample includes 20 food service directors from smaller school districts that enroll less than 500 students (54\%), 8 food service directors from mid-size districts that enroll 501-5,000 students (20\%), and 5 from large school districts that enroll 5,000 or more students (26\%).

Enrollments from one participating school are not disclosed.

Responding school districts were assigned to five research regions according to their geographic location. The five regions are defined by the official Alaska State Website (http://www.alaska.gov/kids/learn/region.htm) and are shown in Figure 2.

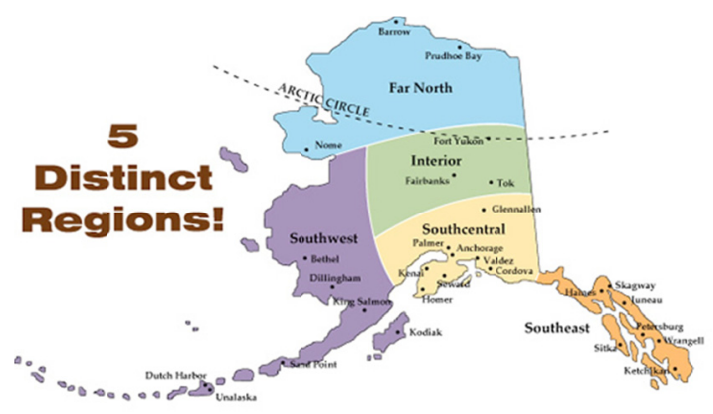

Figure 2. Alaska by regions

The number of school districts from each region and its percentage of total participating districts are presented in Table 1. More participants are from the southeast region (32\%) and fewer are from the interior region (6\%). The other three regions have similar participants.

Table 1. Participating school districts' regions

\begin{tabular}{|c|c|c|c|c|c|}
\hline Regions $(\mathrm{n}=34)$ & $\begin{array}{l}\text { Number } \\
\text { participating } \\
\text { districts }\end{array}$ & $\begin{array}{r}\text { of } \\
\text { school }\end{array}$ & $\begin{array}{l}\% \text { of total participating } \\
\text { school district/total } \\
\text { participated school } \\
\text { districts }\end{array}$ & $\begin{array}{l}\text { Number of school } \\
\text { districts in this region }\end{array}$ & $\begin{array}{l}\% \text { of participating } \\
\text { school districts over } \\
\text { total school districts in } \\
\text { this region }\end{array}$ \\
\hline South east & 11 & & $32 \%$ & 18 & $61 \%$ \\
\hline South central & 8 & & $24 \%$ & 9 & $89 \%$ \\
\hline South west & 7 & & $21 \%$ & 15 & $47 \%$ \\
\hline Far north & 6 & & $18 \%$ & 7 & $86 \%$ \\
\hline Interior & 2 & & $6 \%$ & 5 & $40 \%$ \\
\hline Total & 34 & & $100 \%$ & 54 & -- \\
\hline
\end{tabular}

\subsection{Participating School Food Service Professional's Demographics and Position Duties}

Demographics of participating food service directors are presented in Table 2. There are more female respondents than males (79\% vs. 21\%). Many respondents are between 40 and 59 years old (64\%) and over 50\% of them have worked as a food service director for six years or more. The respondents were asked to report their duties as a food service director. Table 3 shows that many of them reported that staff training, food purchasing, menu planning, and recipe standardization are parts of their responsibilities. More than half of the respondents $(58 \%)$ have two or more duties. 
Table 2. Participant food service professionals' demographics

\begin{tabular}{lll}
\hline$(\mathrm{n}=34)$ & Count & Percentage \\
\hline Gender & & \\
Male & 22 & $79 \%$ \\
Female & 6 & $21 \%$ \\
Total & 28 & 1 \\
\hline Age & & \\
\hline $20-29$ & 1 & $4 \%$ \\
$30-39$ & 3 & $11 \%$ \\
$40-49$ & 9 & $32 \%$ \\
$50-59$ & 9 & $32 \%$ \\
60 or older & 6 & $21 \%$ \\
Total & 28 & 1 \\
\hline Years work as a food service professional & & \\
\hline $1-5$ years & 11 & $48 \%$ \\
$6-11$ years & 5 & $24 \%$ \\
$12-15$ years & 4 & $19 \%$ \\
16 and above & 6 & $9 \%$ \\
Total & 26 & $100 \%$ \\
\hline
\end{tabular}

Table 3. Participant food service professionals' position duties

\begin{tabular}{lllc}
\hline$(\mathrm{n}=34)$ & Yes & Shared responsibilities & No \\
\hline Staff training & $24(70 \%)$ & $8(26 \%)$ & $2(4 \%)$ \\
Food purchasing & $23(68 \%)$ & $6(18 \%)$ & $5(14 \%)$ \\
Menu planning & $21(63 \%)$ & $5(15 \%)$ & $8(22 \%)$ \\
Standardizing recipes & $19(56 \%)$ & $6(18 \%)$ & $9(26 \%)$ \\
Budget allocation & $16(48 \%)$ & $9(26 \%)$ & $9(26 \%)$ \\
Cooking & $7(22 \%)$ & $3(8 \%)$ & $24(70 \%)$ \\
\hline
\end{tabular}

\subsection{How Interested in Serving Local Fish}

Figure 3 summarizes how interested our participants are in purchasing 3 species of Alaskan caught and processed fish. A majority of participating school districts are interested in or very interested in serving local halibut (87\%), salmon (85\%) and Pollock (76\%).

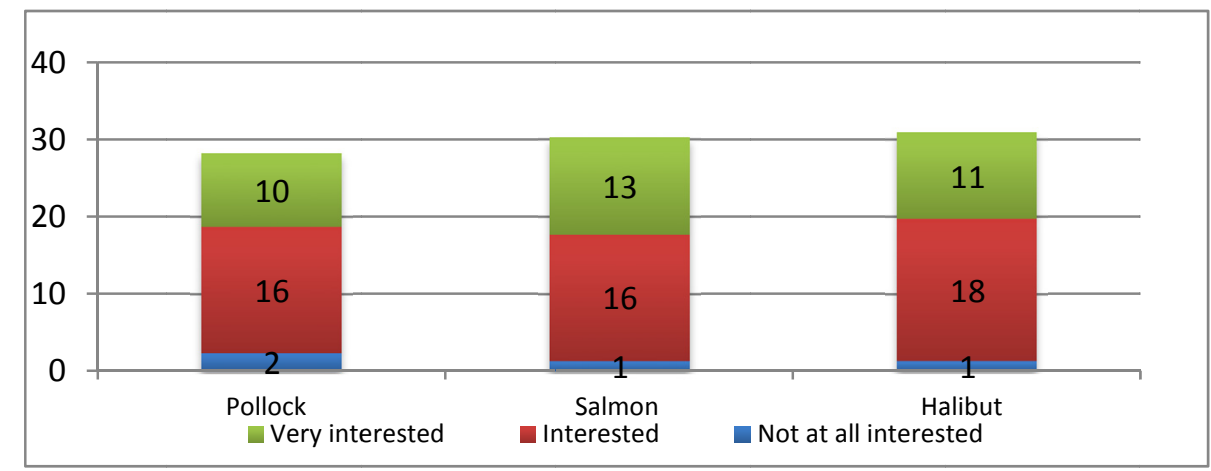

Figure 3. How interested in purchasing local fish $(n=34)$

\subsection{Whether Currently Serve Fish}

The majority of food service directors $(\mathrm{n}=33,70 \%)$ reported that their school district currently serves fish. We then asked them the fish type they serve. Table 4 shows that 18 school districts serve salmon, 15 serve Pollock 
and 9 serve Halibut. Table 4 also shows that smaller and mid-size school districts that enroll fewer than 5,000 students tend to have served these fish. Only two large school districts with 5,000 to 10,000 students have served fish. Districts with 10,000 or more students have also served fish. No information is available to understand why salmon is more popularly served than Pollock and Halibut, even though about half of Alaska's commercial landing is Pollock. Further study may examine the reasons.

Table 4. School districts currently serve local or imported fish, by enrollments and fish type

\begin{tabular}{lllllll}
\hline & Salmon & & Pollock & \multicolumn{3}{c}{ Halibut } \\
\hline (n=34) & Serve & Do not serve & Serve & Do not serve & Serve & Do not serve \\
\hline Less than 300 students & 5 & 4 & 3 & 6 & 2 & 7 \\
300 to 500 students & 4 & 7 & 1 & 10 & 2 & 9 \\
501 to 1000 students & 1 & 1 & 2 & 0 & 0 & 2 \\
1001 to 5000 students & 4 & 2 & 5 & 1 & 3 & 3 \\
5000 to 10,000 students & 1 & 1 & 1 & 1 & 0 & 2 \\
More than 10,000 students & 3 & 1 & 3 & 1 & 2 & 2 \\
Total & 18 & 16 & 15 & 19 & 9 & 25 \\
\hline
\end{tabular}

\subsection{Fish Forms Served or Are Interested in Serving}

We then examined the fish product forms schools already are serving or are interested in serving. The question reads,

"Which of the following forms of fish are served in your school districts? How interested are you in preparing/serving the following forms of fish, if you do not already?"

The information can help fishery processors develop preferred fish forms to supply to the Alaskan school districts. We had a total of 34 respondents but not all of them provided an answer to the above questions. Results show that more than half of the responding school districts are already serving fish sticks or nuggets (56\%) and fresh or frozen fillets (53\%). Fish wraps, tacos, patties and burgers are less likely served (Figure 4). Many respondents indicated that they are interested or very interested in serving fish patties and burgers and fewer are interested in serving fish tacos and wraps.

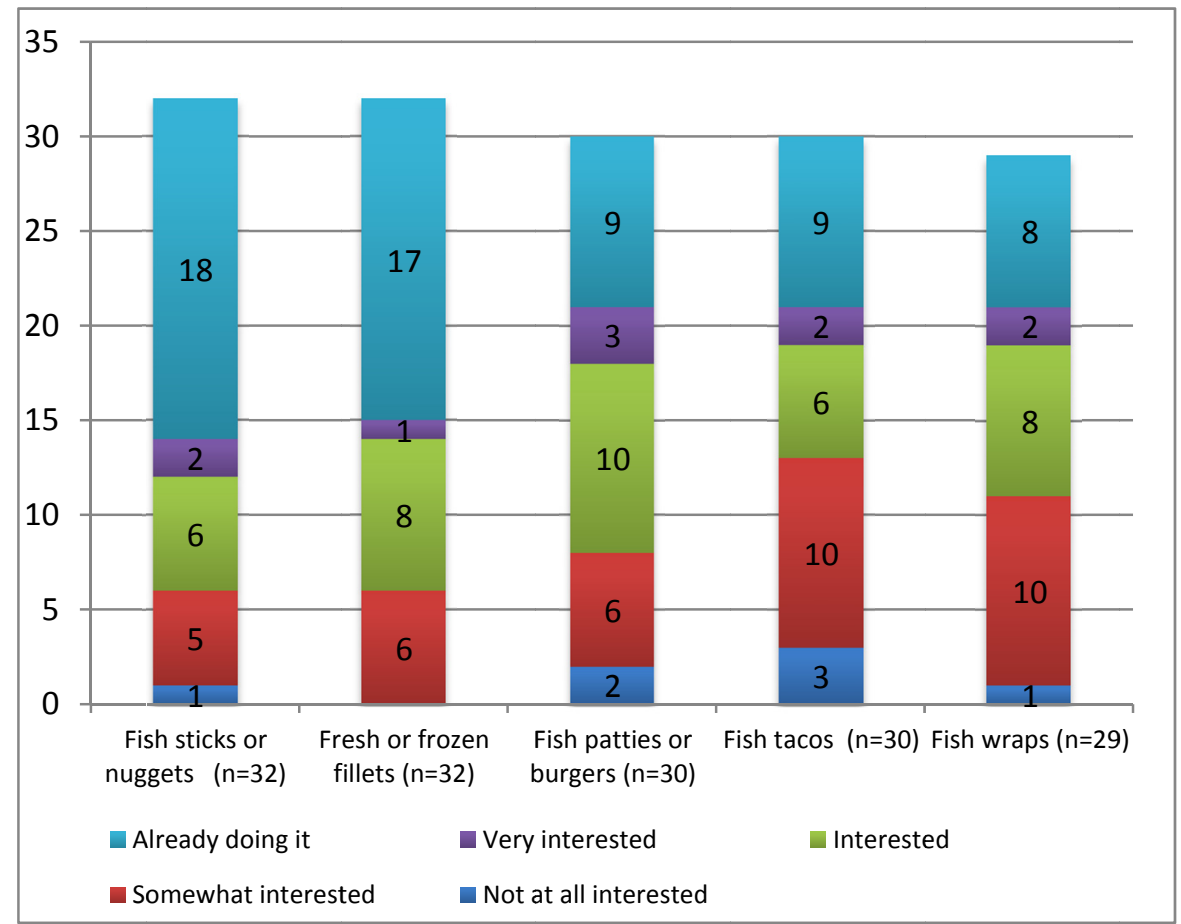

Figure 4. Fish forms served or interested in serving (unit: number of school districts) 


\subsection{Fish-to-School Participation}

Respondents were asked to answer this question:

"How much do the following factors influence your menu planning decisions?"

Most respondents selected "price" $(90 \%)$ and "product availability" $(89 \%)$ as "a lot" important or "completely" important in their menu- planning decisions (Table 5). Given tight budget, most respondents indicated that they carefully consider price when making menu-planning decisions. Nutrition value is another factor that affected $86 \%$ of the respondents. Interestingly, "the uniqueness or novelty of the product" and "utilizing local foods" are two factors least likely to affect menu-planning decisions ( $18 \%$ and $8 \%$ respectively).

Table 5. Factors influence menu planning decisions

\begin{tabular}{lllll}
\hline & not at all & somewhat & a lot & completely \\
\hline Price $(\mathrm{n}=28)$ & 1 & 2 & 15 & 10 \\
\hline $\begin{array}{l}\text { Product availability }(\mathrm{n}=28) \\
\text { Nutrition value of product }\end{array}$ & 0 & 3 & 15 & 10 \\
$(\mathrm{n}=28)$ & 0 & 4 & 15 & 9 \\
Child nutrition label $(\mathrm{n}=28)$ & 2 & 4 & 14 & 8 \\
Student preference $(\mathrm{n}=27)$ & 1 & 5 & 17 & 4 \\
Easy-to-use product $(\mathrm{n}=28)$ & 0 & 7 & 16 & 5 \\
Shelf-life (n=28) & 0 & 10 & 10 & 8 \\
The uniqueness or novelty of & 9 & 14 & 4 & 1 \\
the product (n=28) & & 17 & 1 & 1 \\
Utilizing local foods $(\mathrm{n}=28)$ & 9 & & & \\
\hline
\end{tabular}

Note. * when average the responses, a score was rounded-down. For example, if the score was 2.5 , it was rounded down to 2.

Another question asked respondents their perceived fish price relative to other meats. The results show that only $9 \%$ of the respondents believe fish is less expensive than other meats; more of them (50\%) believe that fish costs the same as other meats; and 31\% believe that fish costs more than other meats (Figure 5).

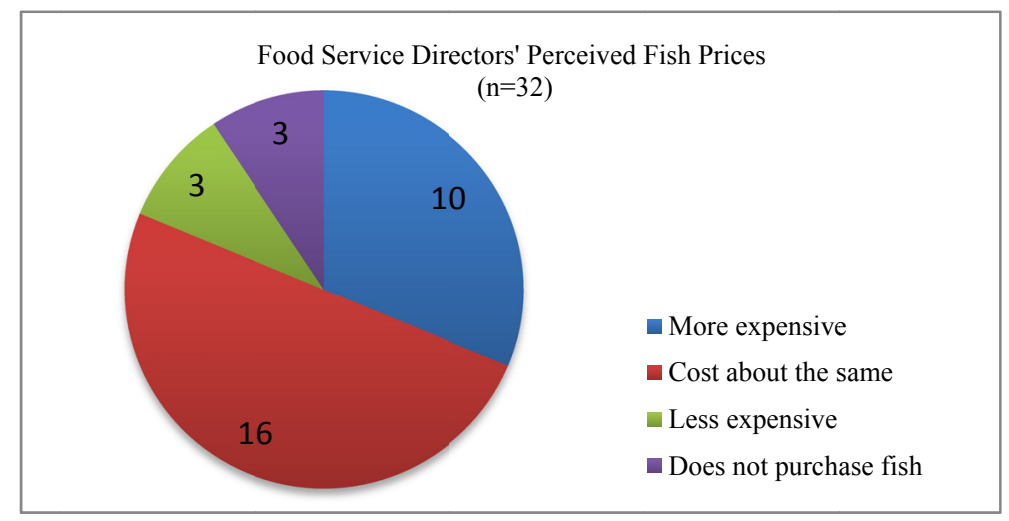

Figure 5. Compared to other meats, how expensive is fish

The last question asked how students prefer fish to other meats. The results suggest that $41 \%$ of the respondents perceive their students like fish less than they like other meats; $53 \%$ believe that their students like fish the same as they like other meats. Only $6 \%$ of them believe their students like fish better (Figure 6). 


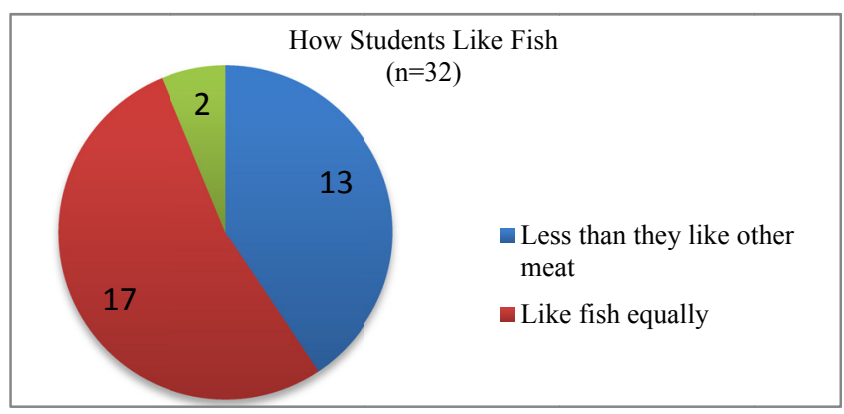

Figure 6. How much students like fish

\section{Conclusions}

This study concludes that many participating food service directors are interested in serving Alaska Pollock, Halibut, and Salmon. The supply of these fish has been abundant: for example Alaska harvested 193,364 thousand pounds of Salmon in 2012 (Alaska Department of Fish and Game, 2012). Besides stated interests from food service directors, our study also reveals that many school districts have already been serving fish. Our study shows that $70 \%$ of all participating school districts have already served fish, either harvested in Alaska or imported from lower 48 states. In regard to the size of schools that serve fish, our sample uncovers that a few relatively large school districts with an enrollment of 5,000 to 10,000 students have not started serving fish. Future fisheries-to-school studies may look for reasons behind this low participation and propose methods to improve students' access to fish in these large school districts. As to the types of fish the school districts serve, schools tend to choose the relatively less expensive Salmon and Pollock rather than the expensive Halibut. Alaska fish processors and their shareholders may address the schools' needs for the more cost-effective fish species and focus on developing Salmon and Pollock menus. Additionally, these fish processors and shareholders may also respond to the school's demand for specific fish forms. Our results indicate that more than $50 \%$ of the responding school districts prefer fish sticks or nuggets and fresh or frozen fillets. Thus, fish processors may consider supplying these different fish items using the relatively inexpensive Salmon and Pollock.

Price, product availability and nutrition value of fish were ranked as the most influential factors to affect menu-planning decisions. Within these three factors, price was listed as the most deterministic factor and nutrition value was ranked the third to change the decision. Thus, Alaska fish processors and their shareholders should consider these two factors by supplying to schools reasonably priced and nutritious fish items. To facilitate common interests, fish processors and schools should plan early to negotiate price and preferred fish items and to allow time for school food service directors to taste test the fish items with students and improve the recipe before finally adopt the fish items. In addition, a pilot study on school posted lunch menus suggests that some schools have fish item served on a weekly base or a monthly base and other schools have them served less often. Thus, schools expect the products to be available when needed and that a stable supply across the semester may be expected. To fish processors and shareholders, supplying fish to school can be a challenging task. However, shortened supply chains and facilitated closer contacts with local suppliers may off-set the negative impact of price on the purchase of local fish, making local fish more preferable than imported fish items.

Students' food preference could greatly affect schools' menu-planning decisions. School food service directors have specified that many students like fish less than they like other meats: only a small portion of $6 \%$ of the survey participants believed their students like fish better than other meats. This lack of interest in fish may become a barrier to the adoption of fish in school meals. To Alaska fish processors and shareholders, develop new recipes that have students preferred product attributes, taste test and revise the recipes to make it attractive to students, and work with school food service directors to develop educational took kits to help students understand the health benefits of eating local fish, are appropriate ways to help students become more interested in fish. This study does not include a taste test to identify preferred fish attributes. Rather, we focus on opinions from food service directors to understand how they evaluate selected fish forms and what factors affect their menu-planning decisions. The next step of our study will focus on parents' and students' preferred fish forms, by analyzing data gathered from a taste test.

\section{Acknowledgement}

This study was supported by Agriculture and Food Research Initiative Competitive Grant no. ALKR-2010-03936 
from the USDA National Institute of Food and Agriculture (Bersamin PI).

The authors want to thank Mrs. Johanna Herron for her help instrumenting and administering the survey and working closely with the PI to design questions that would be understood by food service directors.

\section{References}

Center for Alaska Native Health Research. (2013). Fish-to-Schools. Retrieved from http://www.uaf.edu/canhr/projects/fishschools/

Goldsmith, S. (2007). The Remote Rural Economy of Alaska. University of Alaska Anchorage, Anchorage.

Griffiths, M. (2012). Fish to Schools, published in Juneau Empire. Retrieved from http://juneauempire.com/neighbors/2012-04-15/fish-schools\#.UlxK12Tzai8

Haynes, M. (2010). Farm-to-School in Central Minnesota-Applied Economic Analysis. Retrieved from http://www.cura.umn.edu/publications/catalog/cap-144

Izumi, B., Wright, D. W., \& Hamm, M. W. (2010a). Market Diversification and Social Benefits: Motivations of Farmers Participating in Farm to School Programs. Journal of Rural Studies, 26, 374-382. http://dx.doi.org/10.1016/j.jrurstud.2010.02.002

Izume, B., Alaimo, K., \& Hamm, M. W. (2010b). Farm-to-School Programs: Perspectives of School Food Service Professionals. Journal of Nutrition Education and Behavior, 42(2), 83-91. http://dx.doi.org/10.1016/j.jneb.2008.09.003

Joshi, A., Azuma, A. M., \& Feenstra, G. (2008). Do Farm-to-School Programs Make a Difference? Findings and Future Research Needs. Journal of Hunger \& Environmental Nutrition, 3(2/3), 229-246. http://dx.doi.org/10.1080/19320240802244025

Loring, P. A., \& Gerlach, S. C. (2009). Food, Culture, and Human Health in Alaska: An Integrative Health Approach to Food Security. Environmental Science \& Policy, 12, 466-478. http://dx.doi.org/10.1016/j.envsci.2008.10.006

Martin, S. M., Killorin, M., \& Colts, S., (2008). Fuel Costs, Migration and Community Viability. Institute of Social and Economic Research (ISER), UAA, Anchorage.

\section{Copyrights}

Copyright for this article is retained by the author(s), with first publication rights granted to the journal.

This is an open-access article distributed under the terms and conditions of the Creative Commons Attribution license (http://creativecommons.org/licenses/by/3.0/). 